\title{
David Lewis' Best System Analysis and CP Laws
}

\section{David Lewisin En İyi Sistem Analizi ve İstisnai Yasalar}

\author{
ÖMER FATİH TEKİN (0) \\ Kastamonu University
}

Received: 30.09.2018 | Accepted: 28.03.2019

\begin{abstract}
In this paper, I aim to explore Lewis's best system analysis and how it can accommodate laws with exceptions. The Best System Account has been introduced to provide an alternative view for both minimalist and counterfactual theories of regularities. Simple regularity theory faces problems in which there is some generalization that seems to be a law or some regularities that are established accidentally. It tries to exclude the accidental generalization from the account. However, the best system analysis can solve the problem of how to distinguish between laws and accidents.
\end{abstract}

Keywords: Lewis, best system analysis, cp laws, regularity, generalization.

(C) Tekin, Ö. F. (2019). David Lewis' Best System Analysis and CP Laws. Beytulhikme An International fournal of Philosophy, 9 (I), I-I2. 


\section{Introduction}

In this paper, I aim to explore Lewis's best system analysis and how it can accommodate laws with exceptions. Let's start with a brief introduction to the best system analysis of David Lewis.

David Lewis's best system analysis of laws of nature basically asserts that a "regularity is a law if and only if it appears as a theorem or axiom in that true deductive system which achieves a best combination of simplicity and strength" (Lewis, 1973, pp. 72-77). Unlike the laws in simple regularity theory, which just report facts, the basic duty for laws in Best System analysis is to systematize facts. In this account, as opposed to accidents, laws cannot be taken in isolation. Laws are regularities but not all regularities are laws. Genuine laws here are differentiated from accidental generalizations by being a member of a coherent competing system of regularities, and this is achieved by the simplest and strongest systematization of facts.

In this context, we can give three examples for possible competing deductive systems. First, an enormous lookup-table: the instantiated properties are listed in this system. This would take a beating because it would be very strong, but not simple. Second, there could be a single line like "all electrons have unit charge" (Schrenk, 2006, p. 2). This is very simple, but not strong. There is no chance to win; when we would take a beating in any competition. Finally, "we could have present-day physics" (Schrenk, 2006, p. 2). This is important because this system seems to be reasonably robust, with a combination of all the relevant properties: simplicity, strength, and fit or balance. Moreover, it can take a new position by doing some simpler, stronger and that better fits reorganization. "In any case, note that Lewis operates from the view point of an omniscient being" (Schrenk, 2006, p. 2): "if we knew everything" (Lewis, I973, p. 73). So, it can be seen that physics in the future is likely to come close to the real laws, of course at best (Schrenk, 2006, p. 2).

In Lewis's analysis, winning systems' axioms or theorems are allowed to be laws. There would be no obstacle for the laws of particular sciences such as chemistry, biology, geology, medical sciences etc. in the best system analysis of Lewis. According to Psillos: 
Why simplicity? As Ramsey (I928: I3I) noted, although the choice of axioms (and hence of the fundamental laws) may sound arbitrary, the requirement of simplicity will certainly constrain this choice. And why strength? Obviously, because the deductive system should be as informative as possible vis-à-vis the regularities that hold in the world. But simplicity and strength pull in contrary directions. Hence, a balance should be struck. (2002, p. I49).

And the following quote is important: Lewis says,

the virtues of simplicity and strength tend to conflict. Simplicity without strength can be had from pure logic, strength without simplicity from (the deductive closure of) an almanac ... What we value in a deductive system is a properly balanced combination of simplicity and strength -as much of both as truth and our way of balancing permit. (Lewis, 1973, p. 73).

A group of true generalizations can be deductively generated in a various way. Of these statements, some are simpler than others, whilst some are stronger than others. So one question occurs: how can I choose, as the generalization consists of the true laws of nature? Lewis answers this question cited by Psillos:

We should take into account all systematizations that achieve a good combination of simplicity and strength, and that we should take the laws of nature to be expressed by the axioms (and theorems) that are common in all these systems. Notice also that, although we do not know everything, we can idealize a bit. We can conceive of an ideal deductive systematization based on the assumption that we know everything. (Psillos, 2002, p. 150).

Unlike the laws in Simple Regularity Theory, which just report facts, the basic duty for laws in Best System Analysis is to systematize facts. In this account, as opposed to the accidents, laws cannot be taken in isolation. Laws are regularities, but not all regularities are laws. Genuine laws here are differentiated from accidental generalizations by being members of a coherent system of regularities, and this is achieved by the simplest and strongest systematization of facts.

There are many advantages of the Best System account, such as those I have mentioned above: it protects the laws from accidental generalization by using the deductive system that has simplicity and strength. Secondly, we can see that basic laws and derived laws are separated from 
each other. Consider Kepler's example. Kepler's laws of planetary motion are derived from Newton's law (that is, laws of gravity). There is no opportunity to see this derivation in simple regularity theory, but the best system account allows us to take it nevertheless. Finally, it responds to the counterfactual statements of the theory. We know something about the world and, on the basis of our knowledge about the world, we can say that these are true counterfactuals. So, the best theory consists of both laws and counterfactuals.

However, this position has some disadvantages as well, the most basic being that "whether or not some regularities are expressed in the best deductive system (or systems) of the world will depend on how this deductive system is organized, and on what is allowed to go into it" (Psillos, 2002 , p. I52). On the other hand, it is difficult to find an objective criterion for what determines that system is simple and strong. Finally, it can be seen that, a system might be a very strong one for one scientist, where it might not for another.

In this section, I will show that whether Lewisian best system analysis of law hood allows laws with exceptions. First, I will explain generics and universals and how reconstructing cp laws by generics occurs.

\section{Reconstructing CP Laws by GNCs}

We can start with a comparison between cp laws and strict laws in the BSA by using Generics and Universals. These concepts provide the laws' reconstruction, meaning that strict laws patterned by universals depend on classical logic, "whereas cp laws formalized by Generic NonMaterial Conditionals (GNCs) are based on Delgrande's (1998) nonmonotonic possible worlds semantics for generics" (Unterhuber, 20I4, p. 3). Here are examples for universal and generic statements:

Generics

(га) Trees bloom.

(2a) Poplar trees cannot bloom.
Universals

(Ib) All trees bloom.

(2b) All poplar trees cannot bloom ${ }^{\mathrm{I}}$.

\footnotetext{
I The formalization of the example taken from Unterhuber. (Unterhuber, 20I4, p. 3).
} 
As we can see from the examples above, reconstructed cp laws and generics have some features that might be thought efficient such as Delgrande's, like that $\mathrm{cp}$ laws describe regularities and exceptions can be allowed (Pelletier \& Asher, I997, p. II28f).

Let's start with the logical form of GNCs. GNCs can be formulated as follows: where $\square \rightarrow \mathrm{x}$ binds the variable $\mathrm{x}$ in both the antecedent $\alpha[\mathrm{x}]$ and consequent formula $\beta[\mathrm{x}]$ (Delgrande, I998, p. II6) ${ }^{2}$.

(GNC) $\alpha[\mathrm{x}] \square \rightarrow \mathrm{x} \beta[\mathrm{x}]$

"Formalism, such as GNCs, have been designed to model inferences of agents with incomplete knowledge" (Unterhuber, 20I4, p. II; e.g. Delgrande, I998, p. I22; cf. Brewka, I99I, p. 2f). We can call this formalism as non-monotonic, because defeasible inferences can occur in such formalism. I explain in more detail: here I want to use Unterhuber's formula, but the example is mine: Suppose that Tx and Bx stand for ' $x$ is a tree' and ' $x$ can bloom,' respectively. If ' $T x$ ' also abbreviates ' $x$ is a poplar', then we can display (Ia) and (2a) by the following formulae" ${ }^{3}$ :

$\left(\mathrm{ra}^{*}\right) \mathrm{Tx} \square \rightarrow \mathrm{x} B \mathrm{x}$

$\left(2 a^{*}\right) \mathrm{Tx} \square \rightarrow \mathrm{x} \neg \mathrm{Bx}$

Let's give an example: the tree that has been grown by me in my garden and I call it the King of Trees. Consider that (ra) is an argument that about trees and (2a) comes to believe that the King of Trees is a tree. As a consequence, it seems to be justified to infer that the King of Trees can bloom. However, if there is a belief that the King of Trees is a poplar, then the previous inference should be retracted, and the situation could be summed up as the King of Trees cannot bloom ${ }^{4}$. Here, the inference that the King of Trees can bloom was only defeasibly valid (Unterhuber, 2OI4, p. II).

For example, if an agent only learns that the King of Trees is tree, that agent can infer from ( $\left(\mathrm{a}^{*}\right)$ and $\left(2 \mathrm{a}^{*}\right)$ that the King of Trees can bloom, due to ( $\left.\mathrm{Ia}^{*}\right)$. For instance, if we learn that the King of Trees is a poplar

\footnotetext{
2 The syntactic form of GNCs is the same as that of Schurz's (2002) nomic laws (p. 364f).

3 The formula taken from Unterhuber, but the examples are mine.

4 This interpretation concurs with Pearl's (I988, p. 475) all-I-know interpretation of generic conditionals (Unterhuber \& Schurz, 2013, pp. I4-I6).
} 
(and thus a tree), $\left(2 \mathrm{a}^{*}\right)$ wins over $\left(\mathrm{Ia}^{*}\right)$ and we can infer that the King of Trees cannot bloom (Unterhuber, 20I4, p. I2).

I want to explain why GNCs can be included in BSA in more detail. We can know, thanks to the GNCs, which properties should be seen as exceptional and which as normal in a BSA. This distinction is important, as the following two systems might compete with each other, if we do not draw out this distinction:

System S:

(3) $F x \square \rightarrow x G x$

(4) $\mathrm{Fx} \& \mathrm{Hx} \square \rightarrow \mathrm{x} \neg \mathrm{Gx}$
System S':

(3) $\mathrm{Fx} \square \rightarrow \mathrm{x} \neg \mathrm{Gx}$

(4) $\mathrm{Fx} \& \neg \mathrm{Hx} \square \rightarrow \mathrm{x} \mathrm{Gx}$

It can be seen easily that, there is an equality between these systems S and S', and they seem strong; and thus, they point out the same regularity. In system $\mathrm{S}$, the exceptional part is seen in, $\mathrm{H}$ although it is $\neg \mathrm{H}$ which can be seen as exceptional in the case of S'. It can be seen that "it is quite counter-intuitive to regard both systems as laws of nature" (Unterhuber, 2014, p. 14)

In order to solve this problem as an effective solution, those properties that are seen almost always all space-time points as described in the Best System Analysis should be specified as more normal. According to Unterhuber, "for example, if there are more space-time points which have the properties (i) F, G, and not $\mathrm{H}$ than (ii) F, H, and not G, and not G, one counts (3) and (4) as law candidates rather than (3') and (4'); analogously for ( $\left.3^{\prime}\right)$ and (4') if the frequency pattern is reversed." (Unterhuber, 20I4, p. I4). There are some advantages, such as the following: inferences which are fundamental on GNCs, as identified by the Best System Analysis seem reliable during a case that though to be real more than exceptional ones. In the Best System Analysis GNCs can be matched each other, such as $\left(\mathrm{Ia}^{*}\right)$ and $\left(2 \mathrm{a}^{*}\right)$. After that, one inferences can be seen justifiably that the King of Trees can bloom, given that there is only one knowledge about the King of Trees is that the King of Trees is a poplar. As a result of this, we can deduce that the King of Tress can bloom than it cannot, by the basement of our assumptions. (Unterhuber, 2014, p. 15)

5 These formulas taken from Unterhuber's paper (Unterhuber, 20I4, p. I4). 


\section{Laws with Exception in Lewis's Best System Analysis}

After the general introduction of the best system analysis of Lewis, and reconstructed cp laws by generics, we can turn to the relation between Best System Analysis and Ceteris Paribus laws (cp laws). First of all, I would like to say that Lewis seems not to support cp laws in his account:

Few would deny that laws of nature, whatever else they may be, are at least exceptionless regularities (Lewis, 1986, p. xi).

Admittedly, we do speak of defeasible laws, laws with exceptions, and so forth. But these, I take it, are rough-and-ready approximations to the real laws. There [sic!] real laws have no exceptions, and never had any chance of having any (Lewis, I986, p. I25). As we can see, Lewis's theory seems not to allow for fundamental laws with exceptions. But, there are some, especially non-fundamental laws, such as biology or chemistry, which are ceteris paribus laws; that is to say, laws that suffer from exceptions, and so they need to proviso clauses. These proviso clauses, which have the truth, unfortunately, make a fuss: many philosophers argue that a statement such as "All Fs are Gs, ceteris paribus" cannot make good sense. "Such a phrase, so they say, is either tautologous ('All Fs are Gs, unless not') or stands for a proposition ('All Fs which are also ... are Gs', the gap in which we are unable to close). A theory to tell us how to deal with these challenges is needed" (Schrenk, 2008, p. 4).

We can find various views when examining Lewis's theory of counterfactual conditionals. In that theory, there are possible worlds, and these possible worlds are similar to each other. However, for Lewis, laws of nature in similarity considerations do not have special status. Consider two worlds with the same laws everyone has accepted; there should be a necessary condition for worlds i.e., worlds try to share laws in order to be evaluated as similar (Schrenk, 2008, pp. 4-5).

I could, if I wished, incorporate [a] special status of laws into my theory imposing the following constraint on the system of spheres: $[. .$.$] whenever the$ laws prevailing at $I$ are violated at a world $k$ but not at a world $j$, $j$ is closer than $\mathrm{k}$ to $\mathrm{i}$. This would mean that any violating of the laws of I, however slight, would outweigh any amount of difference from $\mathrm{I}$ in respect of parti- 
cular states of affairs. I have not chosen to impose any such constraint (Lewis, 1973, pp. 72-73).

We can infer from the above quotation that it provides us with an opportunity that loses the hardness of laws. It is not enough that, in order to allow for laws with exceptions, we need to investigate more;

The violated laws are where they are violated. [...] I am using 'miracle' [i.e., violation of law, MAS] to express a relation between different worlds. A miracle at wI, relative to wo, is a violation at wi of the laws of wo. The laws of wI itself, if such there be, do not enter into it (Lewis, I986, pp. 44-45).

When we want to explore laws at wo itself, we still need a violation. A starting point can be similar to the following:

A localized violation is not the most serious sort of difference of law. The violated deterministic law has presumably not been replaced by a contrary law. Indeed, a version of the violated law, complicated and weakened by a clause to permit the one exception, may still be simple and strong enough to survive as a law (Lewis, 1973, p. 75).

Let's explain in more detail: consider a possible world (w), a miniature one with a suitable strong best system, which it is described as S. It has only "ten universally quantified statements (Fs are Gs; all Hs are Js; etc.)" (Schrenk, 2006, p. 4). That miniature world's history can be identified by these statements with their primary conditions. Now, consider another world, which is very similar and denoted by $w^{*}$. The difference between $w$ and $\mathrm{w}^{*}$ is that an F is not a G at a "tiny space-time point" (Schrenk, 2006, p. 4), although the other billions of $F$ instances are all $G$ instances For Schrenk,

Is not it almost certain that in world $\mathrm{w}^{*}$ no other system but $\mathrm{S}^{*}$ is the robustly better system where $\mathrm{S}^{*}$ differs from $\mathrm{S}$ of $\mathrm{w}$ only in that the universally quantified F-law is altered to $\forall \mathrm{u}(\mathrm{Fu} \Lambda \neg @ \mathrm{u} \supset \mathrm{Gu})$ ? (־@u=def object $\mathrm{u}$ is not where the "small, localized, inconspicuous miracle" happens). It is neither there are draws between $S^{*}$ and other systems merely because of this minor exception (Schrenk, 2006, p. 4).

It is very obvious that the above examples depend on the violation's situation. Violation is temporally and spatially restricted because of this; we can see from Schrenk's paper that 
the loss of simplicity, strength and fit we have to accept when we "complicate and weaken" the law by a clause does not affect the robustly bust position of the system that includes that law. (Schrenk, 2006, p. 4)

However, such exceptions have a greater effect on laws in a supposed best system, or the system is the less likely to be the best at the more extended the space-time where violations happen.

After Schrenk's view of Lewis's best system analysis, it would be better to briefly introduce Braddon-Mitchell's view of best system analysis, as compared with Schrenk's view.

In Braddon-Mitchell's paper 'Lossy Laws', he asserts that there are some laws with exceptions in a derivative of Lewis's best system analysis of laws of nature. Braddon-Mitchell prefers enrolling the laws as $\forall \mathrm{u}$ (Fu $\supset$ $\mathrm{Gu})$ even if there is an exception at $(\mathrm{x}, \mathrm{y}, \mathrm{z}, \mathrm{t})$. On this point, it seems that Braddon-Mitchell disagrees with Schrenk. Schrenk's view is $\forall \mathrm{u}(\mathrm{Fu} \Lambda \neg @$ $(\mathrm{x}, \mathrm{y}, \mathrm{z}, \mathrm{t}) \mathrm{u} \supset \mathrm{Gu})$. However, these arguments for the setting up of exceptions look very like each other. Let's have a brief look at BraddonMitchell's view in his own words:

Rather than start with systems that tell only the truth, we start with systems that tell mostly the truth. Not any system that tells a few lies will be admitted of course; the justification for the lies has to be that there are generalizations included which hold for the most part, but because they fail sometimes errors are introduced -the law says all Fs are Gs, but the occasional $\mathrm{F}$ is not and for no apparent reason. We of course reject any such system that fares no better in terms of simplicity and power than ones which tell only the truth, but leave open the possibility that the one which best trades off these desiderata may be one which includes powerful unifying regularities to which, as a matter of fact, there are exceptions, and which thus violates the accuracy desideratum of telling nothing but the truth (Braddon-Mitchell, 200I, p. 266).

Note that a false law is just one which makes a false generalization. It is still a law just so long as the generalization is part of the system which best trades off power, simplicity and accuracy. It is not the old distinction between mere law like generalizations, and the laws (Braddon- Mitchell, 200I, p. 267). If the problem was just ascribed to Lewis, then it is obviously clear 
that Schrenk's view would be more simple. Lewis says, "a version of the violated law may still be simple and strong enough to survive as a law" (Lewis, I973, p. 75). Schrenk's view of laws is derived from Lewis, in the light of this quote, and expresses a similar meaning to Braddon-Mitchell. So Schrenk says, "laws statements are complicated and weakened by such a close" (Schrenk, 2007, p. 93). Moreover, we can see that there is a conflict between Lewis and Braddon-Mitchell. Braddon Mitchell takes the position with lying laws against Lewis's position that a best system "must be entirely true" (Lewis, I983, p. 4I). Lying laws make us consider laws statements, in which at least one might be true. It means that "It is a law that..." should simply mean "it is the case that ..." (Schrenk, 2007, p. 93).

However, Braddon-Mitchell's view has a good point for recording law. His "All Fs are Gs" is definitely a law which cannot stand eligible at the index: "No sophistic twist can be made like in the case of my $\forall \mathrm{u}$ (Fu $\Lambda \neg @(\mathrm{x}, \mathrm{y}, \mathrm{z}, \mathrm{t}) \mathrm{u} \supset \mathrm{Gu})$ which is syntactically strict, and gappy only when seen from the perspective of "the classes of lawful and of outlawed events" (Lewis, I979, p. 55)" (Schrenk, 2007, p. 93).

\section{Conclusion}

In conclusion, we examined the Lewis's theory of law hood in BSA and whether laws with exceptions are allowed. Firstly, Lewis does not accept fundamental or non-fundamental laws with exceptions in BSA. However, Callender and Cohen claim that "Better Best System does not require that aspirants to the title of law hood should be universal and exceptionless. An incomplete generalization may be sufficiently simpler than any complete one, and thereby gain entry into the Best System" (Callender \& Cohen, 20 Io p. 44I). In this context, it can be said that Callender and Cohen (2010) and Schrenk (2007, 2008) are happy with cplaws in a BSA. Schrenk $(2007,2008)$ puts forward a reconstruction of cplaws in a BSA. For Schrenk (Lewis agrees), facts have fundamental features in the BSA. I agree with Lewis and understand that cp-laws are not crucial for Lewis's analysis of BSA; some others like Unterhuber, Callender and Cohen believe that cp-laws perform better than other laws (strict laws). 


\section{References}

Brandon, D.-M. (200I). Lossy Lawes. Oxford, UK: Blackwell Publishers.

Brewka, G. (I991). Nonmonotonic Reasoning: Logical Foundations of Commonsense. Cambridge: Cambridge University Press.

Callender, C. \& Cohen, J. (2010). Special Sciences, Conspiracy and the Better Best System Account of Lawhood. Erkenntnis, 73, 427-447.

Cohen, J. \& Callender, C. (2009). A Better Best System Account of, C. (2009). A Better Best System Account of Lawhood. Philosophical Studies, I45, I-34.

Delgrande, J. P. (1998). On First-Order Conditional Logics. Artificial Intelligence, I05, I05-I37.

Lewis, D. (1973). Counterfactuals. Oxford, Blackwell.

Lewis, D. (I986). Postscript to "A Subjectivist's Guide to Objective Chance". Philosophical Papers, vol. 2. Oxford: Oxford University Press, II4-I32.

Pelletier, F. J. \& Asher, N. (1997). Generics and Defaults. Handbook of Logic and Language. (Eds. J. van Benthem \& A. ter Meulen). Amsterdam: Elsevier, II25II77.

Schrenk, M. (2006). A Theory for Special Science Laws. Selected Papers Contributed to the Sections of GAP.6. (Eds. H. Bohse \& S. Walter). Paderborn: Mentis.

Schrenk, M. (2007). The Metaphysics of Ceteris Paribus Lawes. Frankfurt am Main: Ontos.

Schrenk, M. (2008). A Lewisian Theory for Special Science Laws. Selected Papers Contributed to the Sections of GAP.6. (Eds. D. Bohse \& K. Dreimann, \& S. Walter). 6th International Congress of the Society for Analytic Philosophy. Paderborn: Mentis.

Schurz, G. (2002). Ceteris Paribus Laws: Classification and Deconstruction. Erkenntnis, 57, 351-372.

Unterhuber, M. (20I4). Do Ceteris Paribus Laws Exist? A Regularity-Based Best System Analysis. Erkenntnis, 79, I833-1847.

Weatherson, B. (20I4). David Lewis. http://plato.stanford.edu/entries/david-lewis. 
Öz: Bu çalıșmada, Lewis’in En İyi Sistem analizini ve bu sistemin istisnai yasalara nasıl yer verdiğini açıklamayı hedeflemekteyim. En İyi Sistem hesabı, hem minimalist hem de karşı olgusal düzenlilik teorileri için alternatif bir bakış açısı sağlamak amacıyla bașlatılmıștır. Basit düzenlilik teorisi bir yasa gibi görünen bazı genellemelerin ya da tesadüfi olarak kurulan bazı düzenliliklerin olduğu sorunlarla karșı karșıyadır. O tesadüfi genellemeyi hesabından çıkartmaya çalıșır. Fakat bununla birlikte, en iyi system analizi yasalar ve tesadüfler arasında nasıl ayrım yapılacağı sorununu çözebilir.

Anahtar Kelimeler: Lewis, en iyi sistem analizi, istisnai yasalar, düzenlilik, genelleme. 